\title{
Extent of Adoption level of Improved Maize Production Technology in Saharsa District of Bihar, India
}

\author{
Sarvesh Kumar* and O.P. Mishra \\ Department of Extension Education, Institute of Agricultural Science, \\ Banaras Hindu University, Varanasi-221005 (U.P.), \\ *Corresponding author
}

\begin{tabular}{|l|}
\hline Key w or d s \\
Adoption level, \\
Improved Maize \\
Production
\end{tabular}

\section{A B S T R A C T}

\section{Introduction}

There are tremendous opportunities to further enhance maize production in the country. India will need 65 million tonnes of maize by 2050. This increase in production should preferably come from increase in productivity rather than area. The most critical factors to realize this would be enhancement and diversification of germplasm using modern tools and techniques, development of diverse and productive inbreeds and fine-tuning of resource conservation techniques and to bring down cost of cultivation by enhancing resource use efficiency by maize. India has strategic and geographical advantage over other countries towards supply of maize to international market. This include round-theyear production of maize in our country, low freight charges, well-established seed production and marketing network and availability of sea-port. The demand of special type maize like sweet corn, pop corn, oil corn and waxy corn is in increasing trend. Now, more rigorous efforts are being made to fulfil this demand.

\section{Materials and Methods}

The state Bihar was selected purposively because it is one of the prominent Rabi maize growing states in India. Winter maize is a natural gift provided to Bihar with very high yield potential i.e. 8.0 to 9.0 ton per ha. 
Saharsa district of Bihar was selected purposively because it has highest area and production of the maize as compared to other districts of the state. The other resourceful institutions like, KVK \& Agriculture College are also located in this district. Saharsha district comprises 10 blocks. Out of 10 blocks, two blocks i.e. Kahra and Nauhatta were selected through randomly sampling. A complete list of all the major maize growing villages was prepared in consultation with the personnel of revenue and agriculture department from the identified blocks. From the list so prepared, three villages from each identified block were selected on the basis of random selection technique. Thus, in all six villages were selected for the present investigation. All maize growers were taken as the population of the study. From the population a sample of total 220 were selected through proportionate random sampling technique. Numbers of respondents were found to be in proportion to the total population of the maize growers in the concerned village. Total $5 \%$ of sample size is selected from entire maize grower population of concerned village.

\section{Measurement of adoption level}

\section{Extent of adoption of agricultural technology}

The extent of adoption for the recommended package of practices to cultivate high yielding varieties of maize was measured by means of adoption index, developed on the line of adoption intensity index used by Choubey (1972). As purpose was to quantify the extent of adoption of packaging practices for the cultivation of high yielding varieties of maize, this procedure was followed. Ten practices of technology were selected to study the extent of adoption.

To fix weightage based on the intrinsic difficulty of adoption of practices, 50 judges comprising maize breeder, maize agronomist, agronomy students of IAS, BHU were contacted in person with a request to indicate the degree of ease of adoption of selected practice of the technology by the farmers.

The scoring procedure followed for quantifying responses was:

\section{Procedure adopted in the quantification of extent of adoption}

Proportion for each of ten practices (actual/recommended) were calculated and multiplied by the corresponding weight. Then these values of all ten items were summed and divided by 34 , total number of weights. The resulting value was multiplied by 100 to indicate the percentage of the extent of adoption of the package of practice for HYV of maize.

Proportion for each of ten practices (actual/recommended) were calculated and multiplied by corresponding weight. Then, these values of all eight items were summed and divided by 34 the total number of weights. The resulting value was multiplied by 100 to indicate the percentage of the extent of adoption of the package of practice for HYV of maize.

$$
\text { Adoption index of H.Y.V Maize }=\frac{\text { Total Score }}{\text { Total weightage }} * 100
$$

\section{Results and Discussion}

\section{Extent of adoption of recommended maize cultivation practices by the farmers}

The distribution of beneficiaries in different categories was made by working out mean and SD. The mean adoption score obtained was (77.1) and standard deviation (3.61) were computed for the purpose of classifying the extent of adoption level in to three categories namely low level, medium level and high 
level of adoption, in this way groups are as follows:

Farmers who obtained adoption score below 73.00 were categorized as low adopters. Farmers who obtained adoption score from 73.00 to 81.00 were categorized as medium adopters. Farmers who obtained adoption score above 81.00 were categorized as high adopters.

As it is apparent from data in Table 1 fig that maize growers of about 69.5 per cent were found to be in medium adoption, while 19.5 per cent farmers were in low adoption level and only 11.00 per cent of farmers were in high adoption level respectively.

These findings confirm the findings of Dhruw (2008), who revealed that soybean growers had medium adoption level followed by high and low adoption level about improved cultivation practices of soybean.

Furthermore the extent of adoption of recommended maize cultivation practices was also analyzed separately. The relative adoption of all ten practices of recommended maize cultivation was highlighted by ranking their extent of adoption on the basis of adoption index. The adoption index were obtained by multiplying total obtained score of respondents by hundred and divided by total weightage under each practice.

The data presented in the Table 2 indicates that had highest (81.11AI) adoption about soil and field preparation and hence this practice was ranked first. The second highest percentage of farmers had adoption level of (79.77AI) about High yielding varieties (HYVs) followed by Seed rate, spacing and depth of showing $(76.11 \mathrm{AI})$ and Time of sowing $(75.64 \mathrm{AI})$ which were ranked third and fourth respectively. The extent of adoption of recommended maize cultivation practice like Irrigation, weed management, fertilizer application, and Harvesting were moderately known by farmers as they were having 73.18,70.83,70.30,68.85 AI which were ranked fifth, sixth, seventh, and eighth respectively. Lowest adoption was found in plant protection measures $(67.09 \mathrm{AI})$ and seed treatment (66.51AI) hence last ninth and tenth ranks were assigned to them, respectively.

Table.1 Frequency distribution of farmers under different adoption levels of recommended maize cultivation practices

\begin{tabular}{|l|l|c|c|}
\hline S.No. & \multicolumn{1}{|c|}{ Adoption level } & \multicolumn{2}{|c|}{ Respondents (N=220) } \\
\cline { 3 - 4 } & & Frequency & Percentage \\
\hline 1 & Low (score below 73.00) & 043 & 19.5 \\
\hline 2 & Medium (score from 73 to 81) & 153 & 69.5 \\
\hline 3 & High (score above 81) & 024 & 11.0 \\
\hline & Total & 220 & 100.0 \\
\hline
\end{tabular}


Table.2 Practice wise adoption Index of farmers about recommended maize cultivation practices

\begin{tabular}{|r|l|c|c|}
\hline S.N. & \multicolumn{1}{|c|}{ Package of practices } & Adoption Index & Rank \\
\hline $\mathbf{1}$ & Soil and land preparation & 81.11 & I \\
\hline $\mathbf{2}$ & High yielding varities (HYVs) & 79.77 & II \\
\hline $\mathbf{3}$ & Time of showing & 75.64 & IV \\
\hline $\mathbf{4}$ & Seed treatment & 66.51 & X \\
\hline $\mathbf{5}$ & Seed rate, Spacing & 76.11 & III \\
\hline $\mathbf{6}$ & Fertilizer application & 70.30 & VII \\
\hline $\mathbf{7}$ & Weed management & 70.83 & VI \\
\hline $\mathbf{8}$ & No of irrigation & 73.18 & V \\
\hline $\mathbf{9}$ & Plant protection measures & 67.09 & IX \\
\hline $\mathbf{1 0}$ & Harvesting & 68.85 & VIII \\
\hline
\end{tabular}

Measurement of Adoption Behaviour

\begin{tabular}{|c|c|c|c|}
\hline $\mathrm{p}$ & Practices & Weight age & Procedure \\
\hline 1 & $\begin{array}{l}\text { Use of HYV Maize variety } \\
\text { (Soil and Field preparation) }\end{array}$ & 2 & $\frac{\text { actual area }}{\text { potential area }} *$ Weight \\
\hline $2(a)$ & Seed rate & 2 & $\frac{\text { actual seed rate used / acre }}{\text { recommended seed rate / acre }} *$ Weight \\
\hline 2(b) & Seed treatment & 3 & $\frac{\text { Actual dose applied }}{\text { Recommended dose }} *$ Weight \\
\hline $2(c)$ & Spacing $(\mathrm{P}-\mathrm{P})$ & 3 & Actual spacing/Recommended spacing *Weight \\
\hline $2(d)$ & Spacing(R-R) & 3 & Actual spacing/Recommended spacing *Weight \\
\hline 3 & Intercultural Operation & 2 & Actual No of Io/Recommended No Io*Weight \\
\hline 4 & Application of nitrogen & 2 & $\frac{\text { Quantity ofN applied / acre }}{\text { Quantityof N recommended / acre }} *$ Weight \\
\hline 5 & $\begin{array}{l}\text { Application of } \\
\text { phosphorous }\end{array}$ & 2 & $\frac{\text { Quantity of } \mathrm{P}_{2} \mathrm{O}_{5} \text { applied / acre }}{\text { Quantity of } \mathrm{P}_{2} \mathrm{O}_{5} \text { recommended / acre }} *$ Weight \\
\hline 6 & Application of potassium & 2 & $\frac{\text { Quantity of } K_{2} 0 \text { applied / acre }}{\text { Quantity of } K_{2} 0 \text { recommended / acre }} *$ Weight \\
\hline 7 & $\begin{array}{l}\text { Application of } \\
\text { micronutrients }\end{array}$ & 3 & $\frac{\text { Actual dose applied }}{\text { Recommended dose }} *$ Weight \\
\hline 8 & Irrigation & 2 & $\begin{array}{l}\text { Actual No of irrigation/Recommended No of } \\
\text { irrigation*Weight }\end{array}$ \\
\hline 9(a) & Herbicides & 3 & $\frac{\text { Actual dose applied }}{\text { Recommended dose }} *$ Weight \\
\hline 9(b) & Insecticides/pesticides & 3 & $\frac{\text { Actual dose applied }}{\text { Recommended dose }} *$ Weight \\
\hline 10 & Harvesting & 2 & Actual yield/Recommended yield*Weight \\
\hline
\end{tabular}


The scoring procedure followed for quantifying responses was:

\begin{tabular}{|l|l|c|}
\hline Sl. No. & \multicolumn{1}{|c|}{ Particular } & Score \\
\hline $\mathbf{1}$ & Very difficult & 5 \\
\hline $\mathbf{2}$ & Difficult & 4 \\
\hline $\mathbf{3}$ & Neither difficult nor easy & 3 \\
\hline $\mathbf{4}$ & Easy & 2 \\
\hline $\mathbf{5}$ & Very easy & 1 \\
\hline
\end{tabular}

The mean score from judged responses were rounded to the nearest whole number for each practice and assigned weightage for the respective practice.

It was found that $153(69.50 \%)$ of total maize growers were found to be from medium adoption level group, followed by 43 $(19.50 \%)$ respondents were reported from the group of low adoption level and $24(11.00 \%)$ respondents were in the high adoption level. The findings indicate that, (81.11AI) adoption about soil and field preparation and hence this practice was ranked first. Lowest adoption was found in plant protection measures (67.09 $\mathrm{AI})$ and seed treatment $(66.51 \mathrm{AI})$ hence last ninth and tenth ranks were assigned to them, respectively. It was observed that there was a significant difference among all farmers with regard to adoption of improved maize cultivation technology.

\section{References}

Chaube, C.L. 1972. A study of differential adoption of high yielding wheat

\section{How to cite this article:}

Sarvesh Kumar and Mishra, O.P. 2018. Extent of Adoption level of Improved Maize Production Technology in Saharsa District of Bihar. Int.J.Curr.Microbiol.App.Sci. 7(07): 23732377. doi: https://doi.org/10.20546/ijcmas.2018.707.276 varieties technology as related to influence by selected demographic, socio-phychological and political variables in Sehore district, Madhya Pradesh. Ph.D. Thesis, Division of Agril Extension, IARI, New Delhi.

Dhruw, K.S. 2008. A study on adoption of recommended maize production technology among the farmers of Kanker district of Chhattisgarh state. M.Sc. (Ag.) Thesis, Indira Gandhi Krishi Vishwavidyalaya, Raipur

Source: http://www.brandbharat.com/ english/bihar/bihar_census_2011.html retrieved on 12 January 2016 at 11.23 $\mathrm{pm}$

Source: Data Book, ICAR, 2016 retrieved on 2 December 2015 at $11 \mathrm{am}$.

www.iimr.nic.in retrieved on 04 December 2015 at $7 \mathrm{pm}$. 